Article

\title{
Citizen Participation in Digitised Environments in Berlin: Visualising Spatial Knowledge in Urban Planning
}

\author{
Ajit Singh ${ }^{1, *}$ and Gabriela Christmann ${ }^{1,2}$ \\ 1 Dynamics of Communication, Knowledge and Spatial Development Research Department, IRS-Leibniz Institute for \\ Research on Society and Space, 15537 Erkner, Germany; E-Mails: ajit.singh@leibniz-irs.de (A.S.), \\ gabriela.christmann@leibniz-irs.de (G.C.) \\ ${ }^{2}$ Department of Sociology, School of Planning Building Environment, TU Berlin, 10623 Berlin, Germany \\ * Corresponding author
}

Submitted: 15 March 2020 | Accepted: 25 May 2020 | Published: 26 June 2020

\begin{abstract}
Digital information and communication technologies influence not only on urban planning but also citizen participation. The increasing level of politically driven involvement of the public in urban planning processes has led to the development of new participatory technologies and innovative visual tools. Using an empirical case study, the article investigates a completed participation process concerning an e-participation platform in Berlin, while focusing on the following questions: (1) How are visualisations communicatively deployed within e-participation formats? (2) In what ways do citizens communicate a kind of spatial knowledge? (3) Which imaginings of public urban space are constructed through the use of visualisations? The exploration of the communication conditions and the 'methods' employed will demonstrate the way participants visually communicate their perceptions and local knowledge as well as how they construct their imagining of urban places. In this context, visualisations in participation processes are understood as products of 'communicative actions' (Knoblauch, 2019) that allow people to present their visions in ways that are more understandable and tangible to themselves and others. Within this context, by the example of the state-driven e-platform 'meinBerlin' a discussion will trace how far digitalised and visualised communicative actions from Berlin residents contribute to the social construction of urban spaces and the extent to which they can be considered a part of cooperative planning.
\end{abstract}

\section{Keywords}

citizen participation; digitised environments; e-participation; meinBerlin; spatial knowledge; urban planning; visual methods; visualisations

\section{Issue}

This article is part of the issue "Visual Communication in Urban Design and Planning: The Impact of Mediatisation(s) on the Construction of Urban Futures" edited by Gabriela Christmann (Leibniz Institute for Research on Society and Space, Germany), Christoph Bernhardt (Leibniz Institute for Research on Society and Space, Germany) and Jörg Stollmann (TU Berlin, Germany).

(C) 2020 by the authors; licensee Cogitatio (Lisbon, Portugal). This article is licensed under a Creative Commons Attribution 4.0 International License (CC BY).

\section{Introduction}

Since the second half of the 19th century, approaches to urban design and planning for the emerging modern industrial society have been subject to perpetual reorientation and change, which coincided with the age of rapidly developing (digital) information and communication technologies. Historically, an extensive mediatisation-and digitisation, more recently-of communication processes has taken place with increasing speed. Accordingly, in the field of urban planning, there is an observable trend involving the integration of innovative media technologies and digital tools in planning processes, particularly in the sub-field of public participation, which includes citizens in the processes of creating, communicating, and visualising urban futures. 
A core question for us, which addresses a gap in the research, is: how do digital tools and their social uses influence the communication of perceptions and conceptualisations of urban spaces? Furthermore, how can the (visual) communication and communicative construction of urban futures be best described? Using the example of a digital participation platform in Berlin, Germany, we will examine a distinct participation process concerning the topic: 'Report Noise Sites!' (Lärmorte Melden!). With this case study, we will break down the aforementioned core question into three further queries:

(1) How are visualisations communicated within e-participation formats?

(2) How do citizens communicate spatial knowledge?

(3) Which conceptualisations of the public urban space are constructed through the (re)use and (re)design of visualisations?

Our analysis will employ a sociological, or to be more specific: an ethnomethodological approach (Garfinkel, 1967), which will focus on the description of citizens' 'methods' of communicating on an e-platform.

The article begins with an overview of the broader context of the study, which will sketch out the key arguments in both public debates and research literature concerning citizen participation, including e-participation, which will follow in Section 2. After that, we will introduce our case study, the 'Report Noise Sites!' online survey, which was administrated on the e-platform 'meinBerlin' (Section 3). The methodological approach applied and the process of analysis through which texts and images regarding residential communication will be described in Section 4, while Section 5 will examine how participants linguistically and visually conceive of noise spaces in Berlin. Section 6 will conclude.

\section{The Context: Citizen Participation and e-Participation in Society and Research}

Media discourses and the growing body of interdisciplinary research studies show that citizen participation in urban planning processes has become a central socio-political issue not only in Germany but throughout the world (e.g., Diller, 2015; Gribat, Kadi, Lange, Meubrink, \& Müller, 2017). Both civil-society actors and political actors share the common interest of fostering a more inclusive approach that more directly involves citizens in the planning process and focuses on obtaining social consent to development projects and decisions through expanded public participation. In the spirit of deliberative democracy, participation translates to an approach that emphasises the maintenance of an open dialogue and the communicative involvement of citizens in decision-making processes (e.g., Barber, 2003; Dahl, 1971; Giddens, 1994;).

Outside the abstract domain of democratic theory and legal procedure, discussions concerning how public participation can be practically implemented should not be overlooked. Research literature on the subject continues to grapple with understanding the effects and extent of the public's participation, particularly whether such efforts genuinely increase citizens' involvement in the decision-making process or in how far they merely produce cultures of 'particitainment' (as a connection between the two words 'participation' and 'entertainment'; Selle, 2011). Additionally, debates are also preoccupied with questions related to what forms of participation are most adequate for each stage of the planning process. Indeed, Arnstein provides one of the most prominent approaches used in differentiating the degrees of participation. In the "ladder of citizen participation," Arnstein (1969, p. 217) describes three levels of participation: non-participation, tokenism and citizen power. In her description, she elucidates the inseparable link between participation and power and that eight sub-levels of participation can be distinguished where the share of power for citizens increases from level to level. Arnstein's concept of participation indicates that citizens engage in actions that go beyond a mere consultation or a local knowledge transfer; rather, they are understood as cooperating partners. Keeping this theoretical approach in mind, one can observe throughout the 1960 s and 1970s (i.e., Habermas, 1962; Lefebvre, 1968) as well as the 1990s (i.e., Healey, 1992, 1997), the rapid development of concepts related to the enhanced involvement of civil-society actors in political and urban planning processes.

The market has also responded to the increased need for participation, which can be reflected in the development of a 'participation industry' over the years. In addition to urban planning offices, companies have also begun to specialise as 'participatory service providers' as they develop technical instruments and initiate (e-)participation formats. As participation has grown into a more institutionalised practice in Germany, a steady demand for participation formats has followed, which has led to the creation of numerous new norms as well as inflexible procedure patterns regarding the inclusion of citizens in the planning process. Given the extensive bureaucratisation that has taken place, it is not surprising that such procedural developments have drawn criticism, which can also be understood the result of a reflexive politicisation of civil society (cf. Beck, 1994). The emergence of a participation industry-a reference to the concept, 'cultural industry' (Horkheimer \& Adorno, 1944/2003)-can be understood as a consequence of the neoliberalisation and commodification (Harvey, 2005) of urban planning and participation which is reflected in the increased need for organisations to specialise in the development and application of participation tools as well as the shifting role of the planner, which has grown more akin to that of a moderator of 'event-like' participation formats. Simultaneously, significant changes in information and communication media have profoundly evolved since the 1990s (i.e., Castells, 
1996). As such, the emergence of digital technologies and the increasing 'mediatisation' of society (i.e., Hepp, Hjarvard, \& Lundby, 2015; Knoblauch, 2013) has further enabled unparalleled social accessibility, which catalysed numerous ways of sharing ideas, concepts, knowledge; thus facilitating 'communicative participation.' In this context, e-participation still represents a comparatively novel approach to promoting public participation and is primarily the subject of discourses in e-governance, e-democracy or 'civic culture' (e.g., Couldry et al., 2014; Dahlgren, 2003; Sæbø, Rose, \& Molka-Danielsen, 2010; van Dijk, 2013).

In recent years, an almost unmanageable number of studies have highlighted the many current and historical formats of media-supported (e-)participation around the world, which have coincided with discussions related to the potential of Web 2.0 and social media. With cases involving meta-studies, these potentials are systematically examined in terms of usefulness or the manageability of digital approaches (i.e., Carpentier, \& Dahlgren, 2014; Tambouris et al., 2013). In the field of political participation, elections or donations often captivate the main interest (Bimber, Cunill, Copeland, \& Gibson, 2015). With urban planning, attention is primarily focused on the use and development of digital media, namely in neighbourhood planning (Manuel, Vigar, Bartindale, \& Comber, 2017). In such contexts, the development of digital tools, app-technologies (e.g., Al-Kodmany, Betancur, \& Vidyarthi, 2012; Wilson, Tewdwr-Jones, \& Comber, 2019) or web-based platforms (Steiniger, Pooraziz, \& Hunter, 2016) are implemented and evaluated in planning procedures or are used for scientific crowd sourcing (Szell, 2018) and play a central role in many studies. Falco and Kleinhans (2018), for example, examined 113 globally active digital participation platforms where they observe the "availability and functionalities" of such platforms of co-production in urban development. Among their findings, they discovered that nearly a quarter of the platforms were:

Either used for practical solutions for spatially-bound problems, objects or services in citizens' living environments or targeted towards future-oriented vision, planning or policy making of local areas, neighbourhoods, but also cities (master plans and local community plans). (Falco \& Kleinhans, 2018, p. 64)

In many cases, digitisation has promised that the creation of new interactive and cooperative formats, networks and platforms would also establish new forms of communicative involvement or 'inclusivity' (cf. Hasler, Chenal, \& Soutter, 2017) with regard to participation processes (Brückner \& Märker, 2015; Leitner, 2018). Such promises often followed an implicit normative narrative that the use of digital media would be automatically accompanied by a greater willingness to participate (Hepp \& Pfadenhauer, 2014). However, many initial hopes of digital participation remain unfulfilled, due, in part, to some formatting that proved to be less citizen-centric than assumed. According to van Dijk, preliminary understandings of e-participation can be best described "as the use of digital media to mediate and transform the relations of citizens to governments and to public administrations in the direction of more participation by citizens" (van Dijk, 2013, p. 56).

To summarise, there appears to be an observable trend in studies on e-participation that focus only on the production and implementation of digital tools in an application-oriented and technical way; less common are studies that tackle matters of commitment or the perspectives and motivations of participating citizen (cf. Donders, Hartmann, \& Kokx, 2014). However, an even greater gap in the research is apparent, which our article will address; that is, concerns related to the nature of what happens on platforms, how citizens communicate and contribute to planning processes and what resources and modalities they use to convey their (local) knowledge. Instead of focusing on the evaluation of participation formats or their technological functionality, a citizen-centric perspective will be adopted, which will study both the written (language) and visual communicative actions taking place on e-participation platforms.

We will analyse how digital platforms are used as participation tools where citizens can communicate more directly in planning processes and make their 'voices' heard (Couldry, 2008) and their social position visible. Visibility plays a critical double role: on the one hand it is about socially displaying one's own points of view and the position of those social groups one represents; on the other hand, communication is also visually conditioned-that is, ideas and (subjective) perspectives are no longer generated exclusively through written text but also through the use of map-based methods or other visual tools combined with comments, surveys, etc. Surprisingly, there is not a lot of research which can be referenced on this topic. As such, we will examine how citizens participate and communicate in urban planning processes through digital instruments as well as the role played by linguistic and visual forms of communication. To illustrate our findings, we will employ an empirical case study on the participatory process of an e-participation platform in Germany, which will focus on a poll, 'Noise Protection and Noise Locations in Berlin.'

\section{The Case: Online Platform 'meinBerlin' and e-Participation on Noise Protection}

The online platform 'meinBerlin' was introduced in 2015 by the State of Berlin in Germany and publishes content from the Senate Office of the Governing Mayor (Senatskanzlei des Regierenden Bürgermeistes). The platform is dedicated to providing information on a number of events and projects happening in Berlin and is not used solely for residents to participate in urban planning initiatives. The content and individual projects were set up by responsible employees of the Senate admin- 
istrations, district offices and neighbourhood management. Among its many other features, the site offers citizens opportunities to participate in projects located in their own neighbourhood as well as within city-wide planning processes. This platform is based on the opensource software Adhocracy, from the non-profit association Liquid Democracy, which can be used freely by the government administration as well as local initiatives and organisations.

The main function of the platform is to facilitate participation processes digitally. This applies not only to urban development and planning processes, but also to public discussions concerning participatory budgets or sharing political opinions. A variety of opportunities to participate are made possible through commenting, submitting and evaluating proposals for planning projects. Furthermore, it is possible to visualise and to place suggestions on a digital map. As of March 2020, 48 projects are listed in the online platform, whereas 167 projects have already been completed. One example of a finished participatory project we selected for our analysis is 'Report Noise Sites!'

In modern cities many citizens are exposed to a variety of sensory, acoustic, visual or olfactory stimuli. Especially the experience of noise is a relatively common issue of concern in big cities. This is not only a result of the large number of people, from locals to tourists but also of the many mobility options from cars, motorcycles to trams, which in sum produce a characteristic soundscape. Whether or not these experiences can be classified as 'noise' cannot be answered, yet. On a national (Federal Immission Control Act (Bundesimmissionsschutzgesetz) as well as on an international level, emission limits are legally defined in order to determine the extent of loudness/audibility based on the degree of its harmful quality. 'Noise' as an initially acoustic phenomenon is, however, also directed at the sensory perception of acting subjects and the sensualmeaningful 'typification' (Schutz \& Luckmann, 1974) of sounds as 'noise' based on experiential embodied knowledge. Considering the subjective nature of hearing, it becomes difficult to universalise 'noise' (Maeder, 2013; Maeder \& Brosziewski, 2011). Though the permanent honking on Mumbai's or Cairo's streets might be to the dislike of some people, for others, the experience imparts an acoustic construction of a culturally specific urban identity, while also functioning as an essential form of communication through which road users coordinate their actions with one another. Therefore, noise remains undefined for our purposes. At the same time, noise as a restrictive, disturbing phenomenon also forms the socially shared framework within the participatory process under our investigation, which can be understood as the 'common ground' for communicative action involving participating members.

The city-wide survey 'Report Noise Sites!' is embedded in the larger project 'Berlin Becomes More Silent' (Berlin wird leiser), thus functioning as part of the comprehensive 'Noise Action Plan' (Lärmaktionsplan), which has been conducted and organised by the Senate Department for the Environment, Transport and Climate Protection (Senatsverwaltung für Umwelt, Verkehr und Klimaschutz). The project began in 2013 and will continue between the period of 2018-2023, in the effort to reduce noise emissions throughout the city of Berlin. Since 2018, there have been various analogue formats (events and soundwalks) and digital surveys, which sought to fashion the acoustic setting of the city, making it sensorially perceptible and to identify places considered noisy as well as quiet. This rather extensive knowledge developed through various formats, which allowed conclusions to be drawn concerning future planning processes and will be incorporated into noise action planning.

The 'Report Noise Sites!' poll, which is the chosen case in this article, was conducted and moderated between April and May 2018. Using a digital map for reference, participants were invited to indicate the areas where they were disturbed by noise and how the noise disrupted their physical environment. To assist participants in describing the disturbances they experience, the platform provided four categories of noise from which to select: road noise, rail noise, aircraft noise and 'other'. Citizens were also permitted to submit comments where they could illustrate their personal accounts. Additionally, they were allowed to comment on other citizens' posts, which elicited both positive and negative evaluations. Subsequently, the Berlin Senate Administration collected this feedback and provided detailed responses to the 50 best rated comments.

When looking at the data, which is comprised of least 1589 comments, we quickly realised that only 27 participants used visualisations with their written statements. It is possible that technical features on the platform to create visual material were lacking; however, for those that chose to share images, it appears that communicating a visual mediation of meaning was important to at least to some of the participants involved.

Although visualisations were not used in the survey or later in the report, a qualitative investigation of the images was indispensable for our purposes, which sought to discover their relevance to participants and what subsequent deductions found could hold for planners.

\section{Methodology: Qualitative Analysis of Texts and Images}

As mentioned previously, our study is guided by the following questions: (1) How are visualisations communicatively used within e-participation? (2) How do participants communicate spatial knowledge? (3) Which conceptualisations of urban space are constructed using visualisations? To answer the questions posed, we developed a methodology which allows for in-depth analyses, which can be applied to interpretations concerning both of visual and text-based (written comments) data. 
As such, the study therefore follows the methodological premises of qualitative research. Qualitative empirical research is characterised by the fact that typically case studies are conducted in which non-numerical data are gathered and the analysis of acting and meaning-making is focused (e.g., Glaser \& Strauss, 1967; Silverman, 2006). In our analytical approach we particularly focus on the analysis and interpretation of visual data in the form of various pictures, drawings and photographs which we subsume under the larger umbrella term of 'visualisation.'

From a sociological perspective, we understand visualisations as meaningful devices of human imagination; products that are materialised or embodied constructions created by actors (in our case: citizens) in an effort to make their world tangible to themselves and others. We don't perceive visualisations as mental representations (Lynch, 1960) or as specific communicative tools, but rather, as a part of mediated 'communicative actions' (Knoblauch, 2019), which actors deploy in social situations (in our case: planning processes and/or political decisions). A number of different methodological approaches for the analysis of visualisations exist in the social sciences (i.e., Pink, 2012; Rose, 2016; Schnettler, 2013).

Our study employs the theoretical framework of ethnomethodology (Garfinkel, 1967). Ethnomethodology follows the idea that social reality is created by the actors themselves within a continuous production process. Garfinkel calls this an 'ongoing accomplishment.' This means that actors in social interactions do not simply orient themselves to a (pre)given social order, but rather actively produce this social order as an ordered structure. These kind of practical everyday methods of commonsense reasoning and producing reality can also be understood as 'ethnomethods.' A central assumption of this guiding premise is that people apply distinct procedures and practices to make themselves and the structures they produce visible, understandable or in one word 'accountable' (Garfinkel, 1967, pp. 1-2). Thus, ethnomethodology explores how people perceive everyday life worlds and how (new) social orders are meaningfully constructed in and through processes of social interaction (e.g., on an e-participation platform). The challenge for our study was essentially to transfer these assumptions, which are mostly applied for the analysis of social interactions, to online communication between residents on a e-participation platform.

For analysing participants' written statements and integrating the visualisations used, we have developed our own methodological procedure. Given that visual analysis in combination with the analysis of written comments remains an unconventional practice in this empirical field, it is necessary to develop distinct methodological procedures appropriate to the research subject and for the research questions we have outlined. In our investigation, we analysed participant responses concerning how they attempt to make their personal experiences with urban noise spaces understood. More specifically, we investigated how the participants make their perspectives on the described noise phenomenon 'accountable,' what kind of (visual and linguistic) practices and 'ethnomethods' they apply and what their statements contain: how they visually construct meaning and account 'evidence' on noise spaces for urban planners (see Section 5.1) and how they suggest solutions for the future. At the same time, it was examined how citizens use visualisations in this context. In other words, we looked at the citizens' techniques of showing, demonstrating, 'highlighting' (Goodwin, 1994) and accounting for noise in and through visualisations. Pictures were analysed for what was shown and but also what was not shown. As such, our methodological attitude towards the visual data was to treat what was both shown or not shown in the visualisations as relevant data (see Section 5.2).

In the beginning of the investigation it was already apparent that the participants were faced with solving a pragmatic problem: how can noise be represented in its relation to space? Since it was not technically feasible to represent noise in an acoustic manner on the platform, the participants could only 'display' noise via the use of language and visual imagery. In this context, 'noise' as a sensory phenomenon could only be perceived visually and symbolically through the mediated depiction of places and objects; as such, we consider the investigated visualisations as 'appresentations' (Schutz \& Luckmann, 1989, pp. 131-135). In the tradition of phenomenological sociology appresentations refer to specific syntheses of human consciousness, which bring together two connected features, only one of which only is accessible to direct experience. In this sense, we do not see noise in the pictures, but rather, the visible objects that appresent and account for noise.

\section{Accounting Noise Spaces}

The present section delves more deeply into the empirical cases. The original language of the data collected is in German and the subsequent analysis was also conducted in German; however, they have since been translated into English for our article. We begin our analysis with some examples of the comments posted, which illustrate the linguistic devices participants apply to appresent noise as an invisible phenomenon. Here, we focus on the communicative accounting practices of linguistic sign systems (see Section 5.1). Contrastingly, the examples that follow in the category of 'road noise' turn their attention to the performance of visual communication and the image-text relations (see Section 5.2). The main argument of this section follows our previous discussion concerning ethnomethods of visualising, which result not only from the mechanical production of photographs, which indicate a current situation, but also from the creative contribution of a design that imagines a possible future. Despite the variety of responses collected, what ties them together is the mediation between what is shown and what is appresented. 


\subsection{Describing Noise Spaces: The Use of Language in Written Comments}

We begin our empirical section with the analysis of selected comments from the participants (see Figure 1). Participants who do not use pictures, photographs or drawings to communicate must use other resources or devices to express the type of noise they perceive.

Contributions on the matter of noise are expressed in a variety of ways. First, participants often use expressive verbs (e.g., bluster, clatter, rumble) and metaphorical descriptions of sounds (see Figure 1, first paragraph). Comparisons (e.g., to that of a racetrack) also play a decisive role as does onomatopoeia ("da-da-dada signal," "Rrrhrrrr!!")—which as expressed in the comments, shares a surprising similarity to the language of comics-in the representation of loudness. These expressions provide insight into the participants' imaginations concerning environmental noise in reference to an embodied/corporal and spatial knowledge and ultimately demonstrate how sounds are sensed and perceived.

A second form of expressing the experience of noise includes references to decibel measures of volume. Instead of circumlocutory narrations of subjective perceptions or written descriptions of sounds, the numbers represent a form of evidence is based on objective measurements.

A third category of description involves the presentation of one's own bodily perception which is directly impacted by noise (e.g., through stress, lack of sleep, health problems, etc.). In the second comment (see Figure 1, second paragraph), a resident report how her neighbourhood has changed from an idyllic, quiet sanctuary to noisy, disruptive space where alcohol and drug consump- tion are common. The citizen also complains that the observance of legal regulations and the expectations of maintaining social order are no longer guaranteed by politicians or the police. The once quiet space has grown into a place of fear and, over time, a health risk. The perceived reality of social space (e.g., the neighbourhood) is now sensorially constructed as a place of noise that has exacerbated the commenter's own health.

From an interactionist perspective, language serves the communicative expression of the bodily perception of the affected subject. In addition, the lack of physical co-presence in digital space must also be overcome. While in face-to-face interactions, feelings, emotions or the bodily perception of considerable noise can be interpreted by the display of 'body-glosses' (Goffman, 1971, pp. 122-137); for instance, when actors cover their ears. As such, online communication requires other techniques of self-representation and externalisation. Therefore, language serves as a means of depicting noise, though only in a symbolic manner.

\subsection{Visual Communication and the Construction of Noise Spaces}

Before we look more closely at two selected visual examples, we have included a small self-compiled selection of images uncovered in the data which give a first overview of the diversity of the images.

As mentioned, only 27 participants took advantage of the opportunity to include images in their comments. The images can be distinguished in terms of their form and how they are presented corresponding to the pregiven categories (road noise, rail noise, aircraft noise and 'other') on the platform.

\section{Noise by cars and trams}

On the Holtei Street between Wühlisch Street and Boxhagener Street, drivers are stepping on the gas. Squeaky wheels and howling engines are a daily occurrence. In addition, the tram traffic on the crossing Boxhagener Street screeches and grinds aggressively. The loud warning signal of the tram doors at the Boxhagener Street/Holtei Street stop is also a noise factor, especially at night, as well as the drunken tourists who often wait here for the tram.

(Source: https://mein.berlin.de/mapideas/2018-02070/)

\section{Noise source loud music and meeting point for beer drinkers and drug addicts - evenings and nights}

Actually, it is very idyllic and a nice quiet area at the Seegeluchbecken in Reinickendorf, but in the last few years it has also become a source of noise. Several times a week, in the evening until the night and longer, parties are celebrated with alcohol and drugs and loud music with speakers. My family and I cannot rest at night - I often call the police. However, the police do not often have time for people affected by the noise, despite there being a noise protection law. The police are responsible for compliance with the law. The public order office is not responsible after $10 \mathrm{p} . \mathrm{m}$. Unfortunately, I run into brick walls. There is no remedy in sight from the police, the environmental office, or the politicians. It would be nice if one of them would take care of the problem. The neighbours are afraid and do not dare to make calls.

We long for peace - I am already over 70 years old and I would like to get my high blood pressure under control. Thanks for your project, hopefully it will be successful.

(Source: https://mein.berlin.de/mapideas/2018-02668/)

Figure 1. Examples of written descriptions of noise (authors' own translation). 


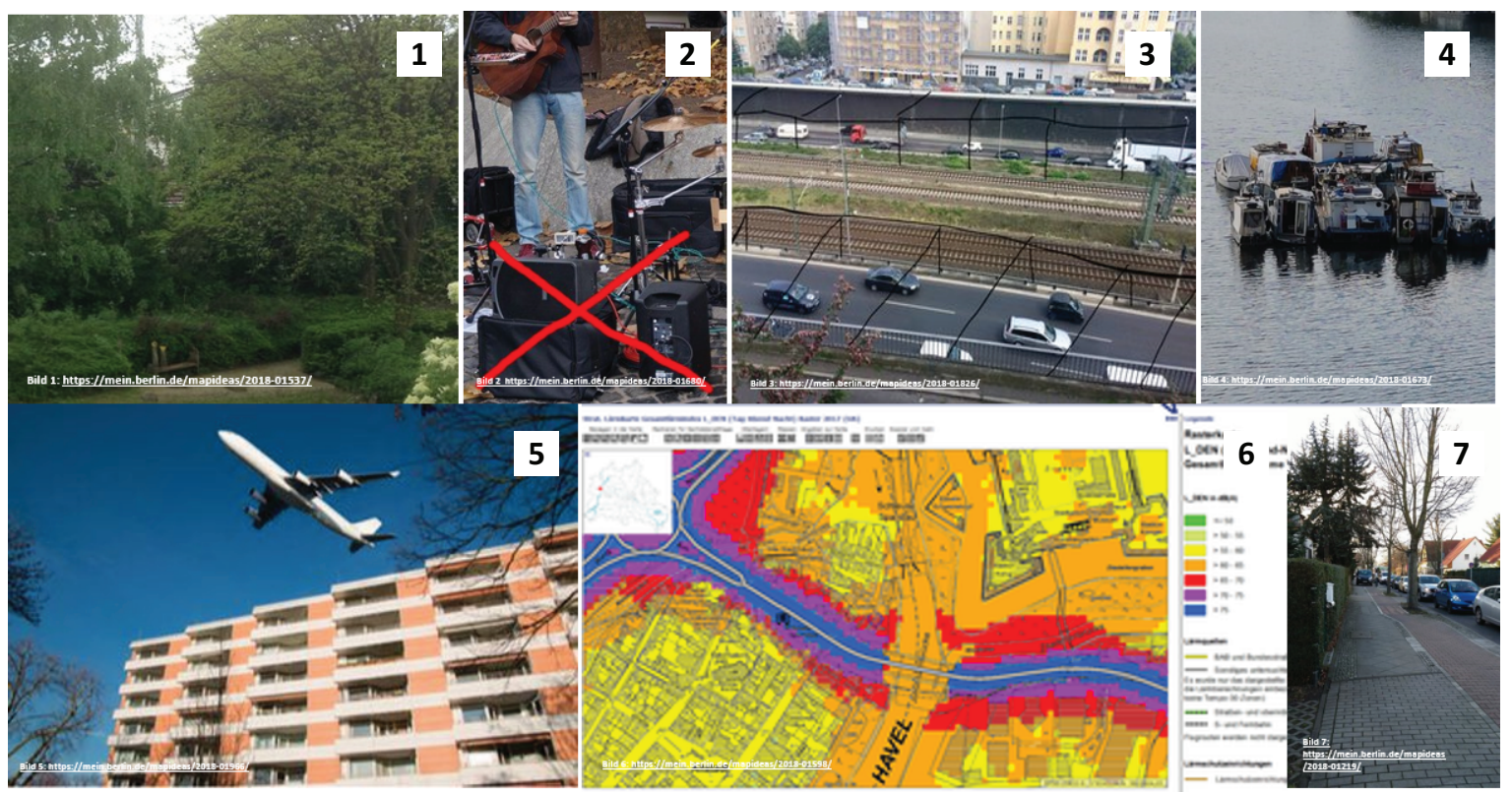

Figure 2. Collage of communicated noise visualisations by citizens. Compiled by the authors based on images from the 'meinBerlin' platform.

The collection includes a broad range of images (see Figure 2), which self-made as well as professional photographs, plans, noise maps and flyers. With some representations, it is not always clear whether participants have created their own images or whether they have been taken from the internet or other sources. References are rarely found, which makes it difficult to assess whether the photo shows an actual place in Berlin (see Figure 2, pictures 3 and 4) or a completely different one altogether (see Figure 2, pictures 1 and 5). Only from the 'amateur' quality and/or the perspectives of certain photographs can it be postulated that they are self-made. Thus, some photos seem ambiguous at first glance (see Figure 2, pictures 1 and 7), which suggests a more thorough analysis of the image is required. Noise maps (see Figure 2, picture 6) or other digitally processed images are taken from administration websites or reports. Some images are 'manipulated' (see Figure 2, picture 2) by 'highlighting' (Goodwin, 1994) specific areas or objects using digitally drawn arrows and edited lines. Additionally, places or 'noise sources' embodied in iconic objects and vehicles (airplane, ship, cars) are presented and pointed out; the intent of which is to generate visual and symbolic evidence for the phenomenon of noise. Interestingly, humans are less often seen as 'appresentation' of noise than objects, possibly due to rights and laws on privacy. A final point of reference regarding the meaningful classification of the images results from their relational arrangement to a more or less detailed written description. In this respect, however, a distinction has to be made as to whether some images are merely a symbolic illustration or if they were actually taken from the respective lifeworld of the citizens concerned. In any case, a thorough examination from an analytical perspective of the corresponding visualisations is required.
5.2.1. Noise and the Appresentation of the 'Traffic Island.'

In our next example, we will illustrate how images are communicatively used for reporting and displaying the phenomenon of noise. In this respect, we follow the aforementioned methodical approach. The following set of images can be tentatively described as a traffic situation.

Starting with a description of Figure 3 (left), a federal road with two different traffic flows is shown. In the image, it appears to have rained recently because the street seems to be wet. The dark-coloured car on the left side of the picture passing the photographer, is the principal focus. Since the car was photographed while it was in motion, the blurred effect caused by the car's movement can be interpreted as a vehicle moving at high speed. If one structures the picture, different 'tracks' and lines can be recognised. First, the street in the centre of the picture is dominant. Second, one can also diagonally split the picture into different parts to focus the view on several aspects of the picture (car traffic, pavement, streets). Third, looking at the side of the street from which the photograph was taken, the spatially marked bus stop comes into view. This us leads to the question: What kinds of objects are put in relation to each other, or more precisely, what does the citizen intend to show (see Figure 3, right)? The noise of the traffic could be one answer, but the picture could also tell another story, which is somehow unseen, yet appresented. For instance, there doesn't appear to be a traffic light or crosswalk near the bus stop, which could stop traffic and make it possible for people to cross from one side of the street to the other. Such absences of could present problems for crossing from one side of the street to the other. When we treat the picture as a whole-that is, consider- 

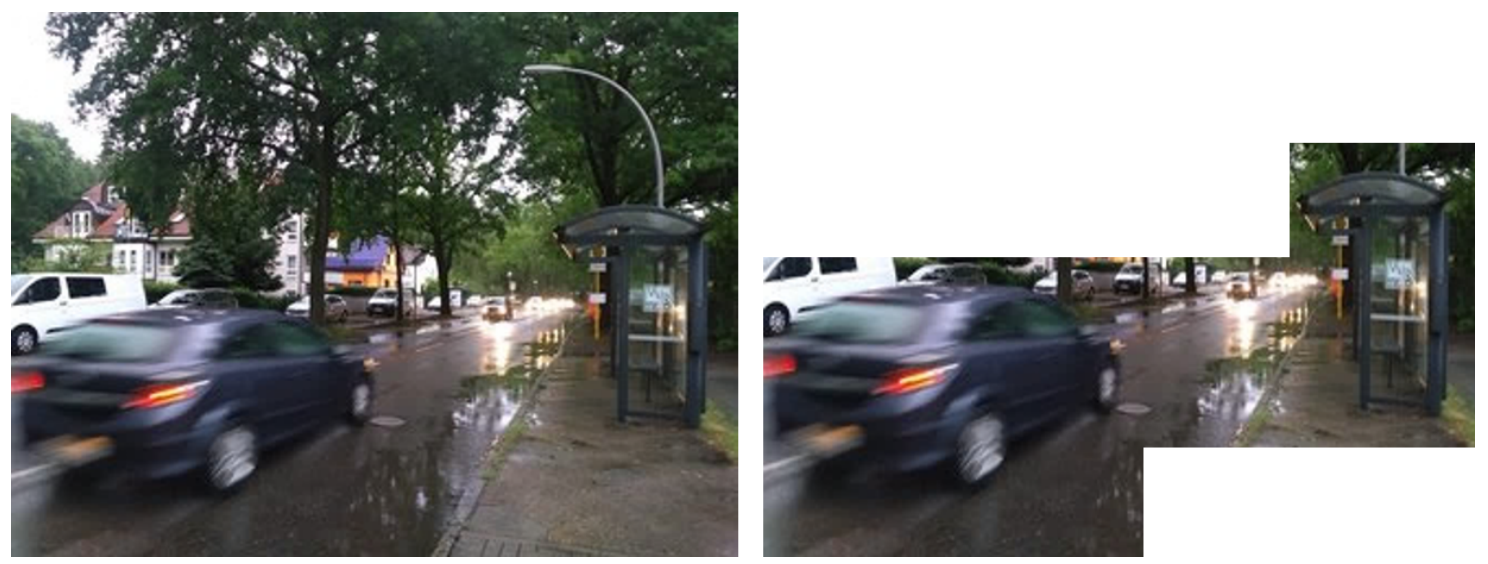

Figure 3. Traffic situations. Edited by the authors based on images from the 'meinBerlin' platform.

ing what is shown what isn't-questions concerning the social situation arise, such as, how can pedestrians safely cross the street?

Turning to participants' written comments, we can see that the topics of our visual analysis also appear in the text (see Figure 4). The resident not only describes the high speed of the cars and the loudness of traffic noise, but he suggests the addition of traffic islands to facilitate pedestrians crossing the road. Although it isn't possible for the picture to directly show what's 'missing' from the citizen's perspective, from the shared account concerning the relation between the existing objects enable us as interpreters by the use of our everyday knowledge to synthesise the gap between the presented and appresented details of those typical situations.

\subsubsection{Imagining and Designing Sustainable Futures}

Drawings possess their own unique quality and are used far less than photos. As shown in the following Figure 5, the drawing is more than an ordinary sketch, but an architectural design.

This rather professionally-made sketch shows the front view of the A 100, a very well-known, loud and heavily frequented motorway in Berlin, which has had a significant impact on the living conditions of the living people there. Figure 5 (left) shows a section of a building on the left side. The building is located directly next to two parallel-running roofed roads as well as four spatially separated railroad tracks, which seem to run alongside a platform. Below the elevated roads and tracks are sev-

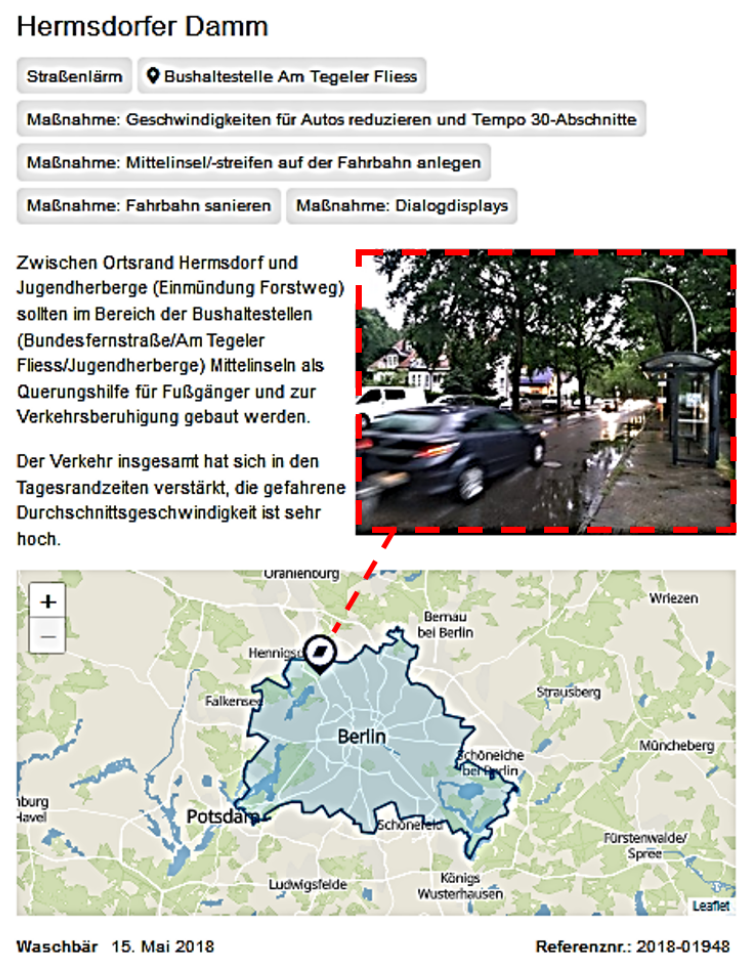

Hermsdorfer Damm

Between the outskirts of Hermsdorf and the youth hostel (junction of the forest road), traffic islands should be built in the area of the bus stops (federal road/Am Tegeler Fliess/youth hostel) as crossing aids for pedestrians and for traffic calming.

The overall traffic has increased during the off-peak times, the average speed is very high.

(Source: https://mein.berlin.de/mapideas/2018-01948/)

Figure 4. Traffic Island (authors' own translation). Edited by the authors based on images from the 'meinBerlin' platform. 

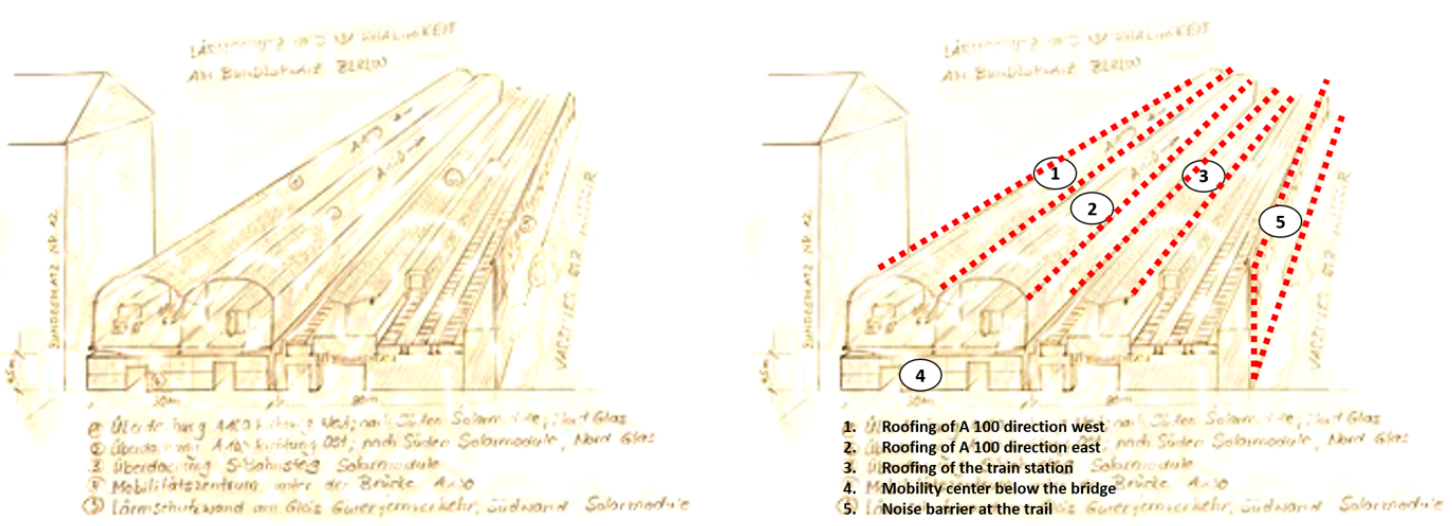

Figure 5. Drawings (authors' own translation). Edited by the authors based on images from the 'meinBerlin' platform.

eral underpasses or tunnel systems. An entrance to the railway station is also indicated in the sketch. The drawing is remarkable in that it shows a unique perspective, a bird's eye view, which appears rather realistic. Indeed, it resembles a cross-section of model showing the inside of the tunnel together with the passing trucks. Since no other background features (e.g., atmosphere, sky, etc.) are shown in the drawing, the focus is entirely on this powerful representation of the traffic flow, which, in a sense, indicates the extreme level of noise that is generated. The drawing also includes an inscription. With the given title, 'Noise Protection and Sustainability at Bundesplatz Berlin,' which is between Innsbrucker Platz and Heidelberger Platz, the sketch provides a programmatic concept of sustainability while connecting it to current discourses in urban studies. Some of the streets are named as well, which clarify the exact location. In addition, some objects in the picture are numbered and explained in a corresponding legend at the bottom of the picture (see Figure 5, right). The central motive of the drawing is to propose a roofing and a sound protection wall and thus a specific design of how sound and noise can be reduced.

Finally, the written comment (see Figure 6.) from the participant explains that the drawing is a proposal on how to make lasting improvements to the noise situa-

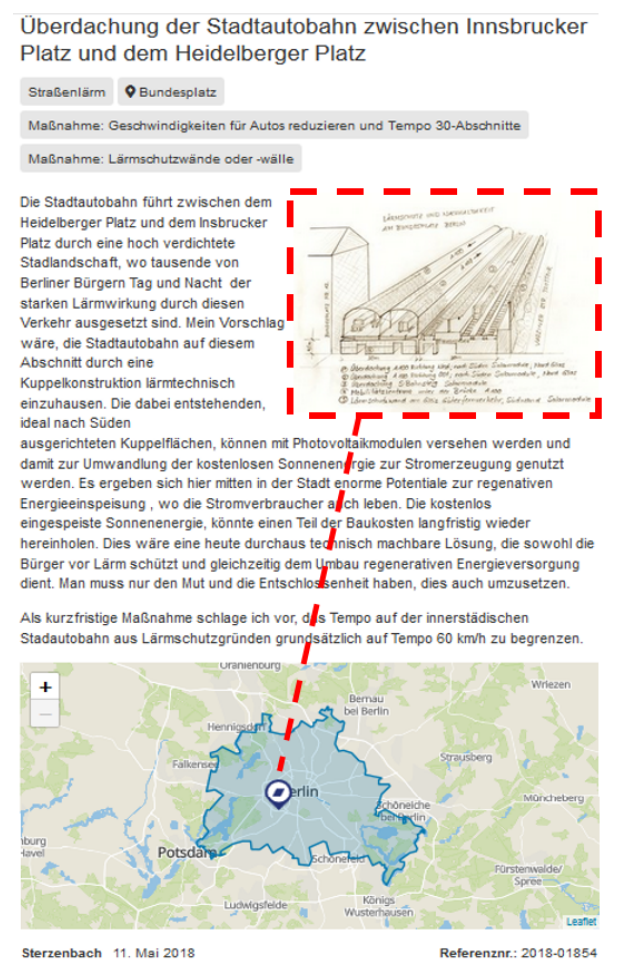

\section{Roofing the urban motorway between Heidelberger Platz and Innsbrucker Platz}

The city motorway between Heidelberger Platz and Innsbrucker Platz runs through a highly dense urban landscape, where thousands of Berlin citizens are exposed to the noise of traffic day and night. My suggestion would be to enclose this section of the city motorway by means of a dome construction. The resulting dome surfaces, which are ideally aligned to the south, can be equipped with photovoltaic modules and be used to convert the free solar energy into electricity. Here in the middle of the city, there is enormous potential for regenerative energy feeding, where electricity consumers also live. The free fed solar energy could even recover a part of the building costs on a long-term basis. This would be a technically feasible solution, which protects the residents from noise while at the same time conserves our regenerative energy supply. One must only possess the courage and the determination to make this conversion possible. As a short-term measure, I propose to limit the speed on the inner-city urban motorway to $60 \mathrm{~km} / \mathrm{h}$ for noise protection reasons.

(Source: https://mein.berlin.de/mapideas/2018-01854/)

Figure 6. Roofing the motorway (authors' own translation). Edited by the authors based on images from the 'meinBerlin' platform. 
tion at the Bundesplatz, which has annoyed a number of other participants on the e-platform. The description of the sketch also includes some special features worth mentioning. In addition to a brief explanation of the noise problem, the citizen also gives a short explanation of the sketch. The citizen illustrates that the concept aims at reducing noise on the one hand. On the other hand, however, an essential aspect is the sustainable construction of a photovoltaic system, which could be used as a cost-effective energy supplier in the future. She interestingly links these thoughts with the final appeal that one just "must have the courage and determination to implement this." Relevant for our analytical purposes, however, is the fact that in this drawing, noise cannot be represented either. Material references are accounted for, including the roof or the walls, which symbolically 'appresent' (Schutz \& Luckmann, 1989) noise and make the phenomenon more or less 'tangible.' The drawing itself proposes and imagines a possible future using the included design of a sustainable built-environment.

\section{Conclusion: Sensorial Construction of Noise Spaces within e-Participation}

In this article analysed how visualisations are used communicatively within e-participation formats and how spatial knowledge is produced by the participants involved. We used the case of an e-participation platform and a specific process in Berlin, which was concerned with the topic of noise protection.

Previous examples demonstrated how citizens produce spatial knowledge using visualisations and otherwise making their corporeal perception of their world visible to planners as well as affected members of the participating public. The knowledge shared is largely anchored in the participant's life world; that is, their neighbourhood and the immediate physical environments. This local knowledge has spatial dimensions and situated as well as bound to certain physical spaces.

We observed how citizens offered detailed descriptions of their acoustic perceptions in spaces of urban life when asked to do so for urban planning purposes. We saw how they expressed their perceptions within the context of a digitised communication space constituted in the e-participation platform, and more so, how they described their experiences with Berlin's noise spaces. For the participants who used visualisations to convey their experiences, we can show that the use of visual devices was employed to transcend the boundaries and limits of the platform's available communication possibilities; that is, where written comments on noise spaces became insufficient at adequately characterising what was being experienced by the participants. The study also revealed that participants were not only willing to indicate their experiences with noise spaces, but some even proposed solutions. In the process of (visually) communicating their substantial solutions, citizens expressed the expectation that their everyday circumstances should be changed and, in some instances, suggested how to go about doing so. In this respect, the communication conditions of the e-platform have activated creative processes. Through the visual proposal of solutions on the digital platform, participants expanded the spatio-temporal limits of their 'zone of operation' (Schutz \& Luckmann, 1974, pp. 41-45) and thus attempted to make a lasting contribution towards a better urban future although they are laypersons.

Lastly, it must be mentioned that the planners' final report on the 'Report Noise Sites!' project only referenced the participants' written comments; it did not include accompanying visual expression. Therefore, the technical means and communication possibilities of the e-platform have not been fully utilised. In this respect, the 'Report Noise Sites!' project represents unmet promises of the e-participation scheme used in the participatory planning process (see Section 2). As with many analogue participation processes, it is mainly local knowledge transfer and citizen consultation that has been organised on the platform. Thus, Arnstein's (1969) ideal of participation was not adequately adopted in the online survey. But it would be a misplaced criticism to conclude that the participants' visualisations were not considered, perhaps for practical or technical reasons, or that this kind of 'data' had no pragmatic relevance to the survey.

From an analytical and practical perspective, this article recommends a reflexive consideration of visualisations in participatory urban planning. There is an observable tendency in planning processes to apply professional visualisations which is being reinforced and shaped by the use of digital tools. Against this background, the 'aesthetic quality' of images produced by laypersons may at first glance appear to be of 'inferior' quality. However, our findings show that images and visualisations from residents should not be simply understood as illustrations to be ignored at worst, or as 'nice' embellishments to enrich the applied (new) participation methods of planners, at best. With our study, we wanted to show the value of taking a closer look at the citizens' submitted visualisations in order to better understand how they visually express perceptions of their environment as well as their needs with regard to future urban spaces. In studying their visual descriptions of noise, we found that they even 'appresented' phenomena through the visual mediation of the 'non-displayable.' We argued that the methodological approach applied in this article can facilitate a reflexive sensitisation of planners for the creative abilities, the everyday competencies of sense-making (ethnomethods) and in sum the 'communicative actions' (Knoblauch, 2019) of citizens who draw attention to distinct problems and present potential solutions for urban futures.

\section{Acknowledgments}

The research in this contribution is part of the project "Mediatisation Processes in Urban Design and PlanningChanges to the Public Sphere" (MedPlan, 2017-2020) 
funded by the Leibniz Competition programme of the Leibniz Association under the project number J68/2016.

\section{Conflict of Interests}

The authors declare no conflict of interest.

\section{References}

Al-Kodmany, K., Betancur, J., \& Vidyarthi, S. (2012). eCivic engagement and the youth. International Journal of E-Planning Research, 1(3), 87-104. https://doi. org/10.4018/ijepr.2012070105

Arnstein, S. R. (1969). A ladder of citizen participation. Journal of the American Institute of Planners, 35(4), 216-224.

Barber, B. R. (2003). Strong democracy. Participatory politics for a new age. Berkeley, CA: Berkeley University Press.

Beck, U. (1994). The reinvention of politics: Towards a theory of reflexive modernization. In U. Beck, A. Giddens, \& S. Lash (Eds.), Reflexive modernization: Politics, tradition and aesthetics in the modern social order (pp. 1-55). Cambridge: Blackwell.

Bimber, B., Cunill, M. C., Copeland, L., \& Gibson, R. (2015). Digital media and political participation. The moderating role of political interest across acts and over time. Social Science Computer Review, 33(1), 21-42. https://doi.org/10.1177/0894439314526559

Brückner, M., \& Märker, O. (2015). e-Partizipation: Elektrifizierung der Bürgerbeteiligung [e-Participation: Electrification of citizen participation]. Standort, 39(2/3), 112-119. https://doi.org/10.1007/s00548015-0393-x

Carpentier, N., \& Dahlgren, P. (2014). Histories of media(ted) participation: An introduction. Communication Management Quarterly, 30(9), 7-14. https://doi. org/10.5937/comman1430007C

Castells, M. (1996). The information age: Economy, society, and culture. Volume 1: The rise of the network society. Oxford and Malden, MA: Blackwell Publishers.

Couldry, N. (2008). Media and the problem of voice. In N. Carpentier \& B. de Cleen (Eds.), Participation and media production: Critical reflections on content creation (pp. 15-26). Newcastle: Cambridge Scholar Publishing.

Couldry, N., Stephansen, H., Fotopoulou, A., MacDonald, R., Clark, W., \& Dickens, L. (2014). Digital citizenship? Narrative exchange and the changing terms of civic culture. Citizenship Studies, 18(6/7), 615-629. https://doi.org/10.1080/13621025.2013.865903

Dahl, R. A. (1971). Polyarchy. Participation and opposition. London and New Haven, CT: Yale University Press.

Dahlgren, P. (2003). Reconfiguring civic culture in the new media milieu. In J. Corner \& D. Pels (Eds.), Media and the restyling of politics (pp. 151-170). London: Sage.
Diller, C. (2015). Bürgerpartizipation und politische Planungsprozesse: Drei kritische Schnittstellen. Eine Auswertung des Forschungsstandes [Citizen participation and political planning processes: Three critical interfaces. An evaluation of the state of research]. pnd/online, 2015(1), 1-20. Retrieved from www. planung-neu-denken.de/content/view/315/41

Donders, M., Hartmann, T., \& Kokx, A. (2014). eParticipation in urban planning: Getting and keeping citizens involved. International Journal of E-Planning Research, 3(2), 54-69. https://doi.org/10.4018/ijepr. 2014040104

Falco, E., \& Kleinhans, R. (2018). Digital participatory platforms for co-production in urban development. International Journal of e-Planning Research, 7(3), 52-79. https://doi.org/10.4018/IJEPR.2018070105

Garfinkel, H. (1967). Studies in ethnomethodology. Englewood Cliffs, NJ: Prentice-Hall.

Giddens, A. (1994). Beyond left and right: The future of radical politics. Cambridge: Blackwell.

Glaser, B., \& Strauss, A. (1967). The discovery of grounded theory. Chicago, IL: Aldine.

Goffman, E. (1971). Relations in public. Microstudies of the public order. New York, NY: Basic Book, Inc.

Goodwin, C. (1994). Professional vision. American Anthropologist, 96(3), 606-633. https://doi.org/ 10.1525/aa.1994.96.3.02a00100

Gribat, N., Kadi, J., Lange, J., Meubrink, Y., \& Müller, J. (2017). Planung als politische Praxis. Zur Einleitung in den Themenschwerpunkt [Planning as political practice. Introduction to the thematic focus]. sublurban. Zeitschrift für kritische Stadtforschung, 5(1/2), 7-20. https://doi.org/10.36900/suburban.v5i1/2.268

Habermas, J. (1962). Strukturwandel der Öffentlichkeit. Untersuchungen zu einer Kategorie der bürgerlichen Gesellschaft [The structural transformation of the public sphere: An inquiry into a category of bourgeois society]. Berlin: Luchterhand.

Harvey, D. (2005). A brief history of neoliberalism. Oxford: Oxford University Press.

Hasler, S., Chenal, J., \& Soutter, M. (2017). Digital tools as a means to foster inclusive, data-informed urban planning. Civil Engineering and Architecture, 5(6), 230-239. https://doi.org/10.13189/cea.2017. 050605

Healey, P. (1992). Planning through debate: The communicative turn in planning theory. Town Planning Review, 63(2), 143-162. https://doi.org/10.3828/tpr. 63.2.422x602303814821

Healey, P. (1997). Collaborative planning. Shaping places in fragmented societies. Vancouver: UBC Press.

Hepp, A., Hjarvard, S., \& Lundby, K. (2015). Mediatization: Theorizing the interplay between media, culture and society. Media, Culture \& Society, 37(2), 314-324. https://doi.org/10.1177/ 0163443715573835

Hepp, A., \& Pfadenhauer, M. (2014). Mediatisierte Partizipation? Kleine Formen der Beteiligung jenseits 
von Medienlogik [Mediatized participation? Small forms of participation beyond media logic]. In F. Krotz, C. Despotovic, \& M. Kruse (Eds.), Die Mediatisierung sozialer Welten. Synergien empirischer Forschung [The mediatization of social worlds. Synergies of empirical research] (pp. 235-162). Wiesbaden: Springer VS.

Horkheimer, M., \& Adorno, T. W. (2003). Dialektik der Aufklärung. Philosophische Fragmente [Dialectic of enlightenment. Philosophical fragments]. Berlin: Fischer. (Original work published 1944)

Knoblauch, H. (2013). Communicative constructivism and mediatization. Communication Theory, 23(3), 297-315.

Knoblauch, H. (2019). The communicative construction of reality. New York, NY: Routledge.

Lefebvre, H. (1968). Le droit à la ville [The right to the city]. Paris: Éditions Anthropos.

Leitner, M. (Ed.). (2018). Digitale Bürgerbeteiligung. Forschung und Praxis: Chancen und Herausforderungen der elektronischen Partizipation [Digital citizen participation. Research and practice: Opportunities and challenges of electronic participation]. Wiesbaden: Springer VS.

Lynch, K. (1960). The image of the city. Cambridge, MA: The MIT Press.

Maeder, C. (2013). Sound analysis. In U. Flick (Ed.), The SAGE handbook of qualitative data analysis (pp. 424-434). London: Sage Publishers.

Maeder, C., \& Brosziewski, A. (2011). Ethnosonographie: Ein neues Forschungsfeld für die Soziologie? [Ethnosonography: A new field of research for sociology?] In N. Schroer \& O. Bidlo (Eds.), Die Entdeckung des Neuen. Qualitative Sozialforschung als Hermeneutische Wissenssoziologie [The discovery of the new. Qualitative Social Research as Hermeneutic Sociology of Knowledge] (pp. 153-170). Opladen: Springer VS.

Manuel, J., Vigar, G., Bartindale, T., \& Comber, R. (2017). Participatory media: Creating spaces for storytelling in neighbourhood planning. In C. Lampe \& M. C. Schraefel (Eds.), CHI'17: Proceedings of the 2017 ACM SIGCHI Conference (pp. 1688-1701). New York, NY: Association for Computing Machinery. https:// doi.org/10.1145/3025453.3025745

Pink, S. (2012). Advances in visual methodology. London: Sage.

Rose, G. (2016). Visual methodologies: An introduction to interpreting visual materials (4th ed.). London: Sage.
Sæbø, Ø., Rose, J., \& Molka-Danielsen, J. (2010). e-Participation: Designing and managing political discussion forums. Social Science Computer Review, 28(4), 403-426. https://doi.org/10.1177/ 0894439309341626

Schnettler, B. (2013). Notes on the history and development of visual research methods. InterDisciplines: Journal of History and Sociology, 4(1), 41-75.

Schutz, A., \& Luckmann, T. (1974). The structures of the life-world (Vol. 1). London: Heinemann.

Schutz, A., \& Luckmann, T. (1989). The structures of the life-world (Vol. 2). Evanston, IL: Northwestern University Press.

Selle, K. (2011). "Particitainment" oder: Beteiligen wir uns zu Tode? Wenn alle das Beste wollen und Bürgerbeteiligung dennoch zum Problem wird ["Particitainment" or: Participating ourselves to death? When everyone wants the best and citizen participation is still a problem]. pnd/online, 2011(3), 1-19. https:// doi.org/10.18154/RWTH-CONV-020780

Silverman, D. (2006). Interpreting qualitative data: Methods for analysing talk, text and interaction. London: Sage.

Steiniger, S., Pooraziz, M. E., \& Hunter, A. (2016). Planning with citizens: Implementation of an e-planning platform and analysis of research needs. Urban Planning, 1(2), 49-64. https://dx.doi.org/10.17645/up. v1i2.607

Szell, M. (2018). Crowdsourced quantification and visualization of urban mobility space inequality. Urban Planning, 3(1), 1-20. http://dx.doi.org/10.17645/up. v3i1.1209

Tambouris, E., Macintosh, A., Dalakiouridou, E., Smith, S., Panopoulou, E., Tarabanis, K., \& Millard, J. (2013). e-Participation in Europe. In J. R. Gil-Garcia (Ed.), e-Government success around the world: Cases, empirical studies, and practical recommendations (pp. 341-357). Hershey, PA: IGI Global.

van Dijk, J. A. G. M. (2013). Digital democracy: Vision and reality. In I. Snellen, M. Thaens, \& W. van de Donk (Eds.), Public administration in the information age: Revisited (pp. 49-62). Amsterdam: IOS Press.

Wilson, A., Tewdwr-Jones, M., \& Comber, R. (2019). Urban planning, public participation and digital technology: App development as a method of generating citizen involvement in local planning processes. Environment and Planning B: Urban Analytics and City Science, 46(2), 286-302. https://doi.org/10.1177/ 2399808317712515

\section{About the Authors}

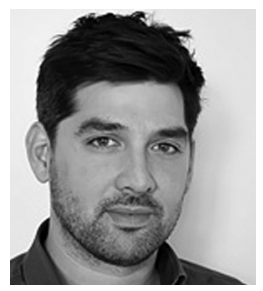

Ajit Singh (PhD) is a Sociologist and a Research Associate at the Dynamics of Communication, Knowledge and Spatial Development research department at the Leibniz Institute for Research on Society and Space in Erkner, Germany. He spent one year as a research fellow at the Global Urban Research Unit at Newcastle University (UK). His research interests include social theories on interaction, visual communication and embodiment, sociology of knowledge, digital mediatisation in urban planning and public participation and qualitative methods. 


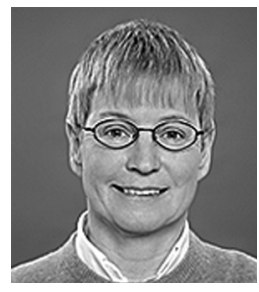

Gabriela Christmann is a Sociologist. She is Head of the research department Dynamics of Communication, Knowledge and Spatial Development at the Leibniz Institute for Research on Society and Space in Erkner, Germany. At the same time, she is Adjunct Professor at TU Berlin, School for Planning Building Environment (Department of Sociology). Her main research fields include the sociology of knowledge, innovation research, theories of space, sociology of planning, communicative constructivism, mediatisation and digitalisation processes. 